\title{
25 Research Square \\ Effects of Forest Structure On Dendroctonus Valens Damage Under Natural and Human Disturbances
}

\section{Zhongyi Zhan}

Beijing Forestry University https://orcid.org/0000-0002-1443-573X

\section{Lixia Wang}

Beijing Forestry University

\section{Linfeng Yu}

Beijing Forestry University

\section{Lili Ren}

Beijing Forestry University

Youqing Luo ( $\nabla$ youqingluo@126.com )

Beijing Forestry University https://orcid.org/0000-0001-5306-8306

\section{Research}

Keywords: Red turpentine beetle, Fire, Stolen felling, Forest landscape structure

Posted Date: July 6th, 2021

DOI: https://doi.org/10.21203/rs.3.rs-643834/v1

License: (c) (1) This work is licensed under a Creative Commons Attribution 4.0 International License. Read Full License 


\section{Abstract \\ Background}

In recent years, the red turpentine beetle (Dendroctonus valens, RTB), an invasive pest species has spread northward along the distribution of pine forests, forming a potential threat to healthy pine forests in North China. Previous studies have shown that natural (e.g., fire) and human (e.g., felling) disturbances can significantly promote bark beetle damage. However, few studies have considered the effect of forest landscape structure on bark beetle damage under disturbance conditions. Here we used generalized linear models and generalized linear mixed models to explore the effects of multi-scale factors on RTB damage under different disturbance conditions (presence or absence) in 109 forest stands in the Heilihe National Nature Reserve, Inner Mongolia.

\section{Result}

Disturbance (i.e., fire and stolen felling) could significantly promote the occurrence of RTB. In the absence of disturbance, small-scale stand factors (i.e., aspect and canopy density) played important roles in the prediction of RTB damage. In the presence of disturbance, forest landscape structure (i.e., forest isolation) was the main factor affecting RTB invasion.

\section{Conclusion}

In the presence of disturbance, the forest structure played an important role in the process of the diffusion of RTB from the surrounding habitat to the disturbance. This study, which emphasizes the potential importance of forest landscape structure on RTB spread, not only provides new insights into understanding the roles of large-scale factors but also assists in the implementation of pest management programs.

\section{Background}

Bark beetle outbreaks are significant natural disturbance in forest ecosystems worldwide (Coops et al., 2006; Negrón et al., 2009; Seidl et al., 2015). Such outbreaks have important ecological impacts on wildlife, forest succession, water quality, forest timber supply, and forest leisure and entertainment functions (Abbott et al., 2009; Klutsch et al., 2009; Mezei et al., 2014). Since 1998, serious outbreaks of red turpentine beetle (Dendroctonus valens, RTB), an exotic invasive pest, have occurred in many provinces of China, which indirectly caused economic loss of totaled $¥ 8.1$ billion (Zhao et al., 2002; Xu et al., 2006). In recent years, RTB has spread northward along the distribution of pine forests, forming a potential threat to healthy pine forests in North China (Yan et al., 2005; Cheng et al., 2015). While RTB outbreaks have led to a large area of continuous tree mortality, beetles are selective in their attack strategy in the initial invasive stage, leading to a patchwork of tree mortality across the forest landscape 
(Nelson et al., 2006; Bone et al., 2013). Identifying the factors that promote RTB outbreaks in the early stage of invasion is crucial for forest managers to predict and mitigate RTB damage.

The dispersal flight of bark beetles depends on their population density (Barclay et al., 2005). In the endemic population phase, bark beetles respond to pheromones and fly in a short distance mainly within the canopy to locate new hosts and mate. In the epidemic population phase, when suitable habitats are exhausted or when beetles enter unfavored habitats, bark beetles may rise above the canopy and follow the wind to travel a long distance to new habitats (Jones et al., 2019). Short-distance dispersal events are more common than long-distance dispersal events. Many studies have shown that forest structure (e.g., the connectivity of host trees and forest fragmentation) can affect the dispersal flight of insect defoliators during the host-searching and colonization processes (Campbell et al., 2008; Castagneyrol et al., 2019; Wang et al., 2019). This effect of forest structure is applicable to the short-distance dispersal flight of bark beetles (Hansen et al., 2016). However, some studies have pointed out that the effects of forest structure, such a large-scale landscape variable, on host selection of bark beetles vary with the degree of pest damage (Raffa et al., 2008; Simard et al., 2012). For example, in the early stage of bark beetle invasion, the main factors affecting bark beetle damage may be small-scale factors such as tree vigor, tree size, and stand characteristics, while forest landscape structure may not play an important role. Considering that most of the studies on bark beetle damage were conducted during the outbreak stage when massive and continuous tree mortality was observed; thus, this view has not been well proved (Simard et al., 2012; Seidl et al., 2015).

Climate change and increasing human activities are alternating the frequency and severity of the disturbances (e.g., wildfires, logging, and bark beetle outbreaks) on forests, thereby increasing the possibility of disturbance interactions (Komonen and Kouki, 2008; Raffa et al., 2008; Seidl et al., 2016). One kind of disturbance may amplify or dampen the possibility and severity of another disturbance through positive or negative feedback (Hart et al., 2015). Many studies have made great progress in exploring the interaction between bark beetle outbreak and other disturbances such as fire (David et al., 2012; Kulakowski and Jarvis, 2013; Westlind and Kelsey, 2019), gap felling (Komonen and Kouki, 2008; Toivanen et al., 2009; Hekkala et al., 2020), and storm (Schroeder, 2009; Havašová et al., 2017). These disturbances can injure pine bole tissues to release ethanol + 3-carene and monoterpene kairomones, which can attract RTB in the surrounding environment to feed (Kelsey and Westlind, 2017, 2018). In addition, the preference of bark beetles to some tree (e.g., tree diameter) or gap characteristics (e.g., the distance from the gap) at the disturbance site was also studied (Komonen and Kouki, 2008; Kulakowski and Jarvis, 2013). However, few research has focused on the effect of forest landscape structure on RTB damage in the presence of other disturbances.

With the northward spread of RTB from Shanxi Province, RTB was found in the Heilihe Nature Reserve for the first time in 2017 (Tang et al., 2019). In recent years, owing to the abundant host resources and lack of natural enemies, the occurrence of RTB was found in many places of this area. However, due to the short invasion history, the Heilihe National Nature Reserve is considered in the early stage of RTB outbreak without extensive tree mortality (White et al., 2005). In addition, fire and stolen felling are the 
most common and widespread ecological disturbances in this area. Extensive RTB damage is observed in the forest stands where these disturbances occur. The main purpose of this study was to investigate the effect of forest landscape structure on RTB damage in the early stage of invasion. At the same time, we also considered the influence of small-scale factors such as tree diameter, canopy density, and soil nutrients on RTB damage under different disturbance conditions. We hypothesize that forest landscape structure plays different roles in the presence or absence of natural and human disturbances.

\section{Methods}

\section{Study area}

The study area is located in the Heilihe National Nature Reserve $\left(118^{\circ} 27^{\prime} ; 41^{\circ} 24^{\prime}\right)$ of Inner Mongolia Province in North China, covering an area of about 27,638 hectares and rising from $750 \mathrm{~m}$ to $1,200 \mathrm{~m}$ above sea level. The mean annual precipitation and temperature of this area are $470 \mathrm{~mm}$ and $6^{\circ} \mathrm{C}$, respectively (China Meteorological Data Service Center, 2021). This area is characterized by the presence of forest patches where the most common tree species is Chinese pine (Pinus tabuliformis, the host tree of RTB), interspersed with larch (Larix principis-rupprechtii), some broad-leaved tree species, and grasslands. The remaining landscape is characterized by agricultural lands and urban areas.

\section{Site Selection And Field Sampling}

May and August are the flight periods of RTB, during which the temperature is suitable for their feeding and spread (Zhan et al., 2020). A total of 109 sample plots, in which the trees showed a continuum of degree of RTB damage, were randomly selected and investigated in August of 2019 and 2020, including 79 plots affected by neither fire (natural disturbance) nor stolen felling (human disturbance), 15 plots affected by fire, and 16 plots affected by stolen felling (Fig. 1). For the sample plots disturbed by stolen felling, a small number of $P$. tabulaeformis (about 3 to 10 trees) were felled, which would not affect the measurement of stand-level factors such as canopy density (described below). The dead pine trees suffered high-severity fire would not attract bark beetles due to their poor physiological conditions, while low-severity fire increases susceptibility of lodgepole pine to mountain pine beetle (Kulakowski and Jarvis, 2013). Therefore, for the sample plots disturbed by fire, we selected those at the edge of the fire scene in 2019 and 2020. Most of the pine trees in our sample plots possess a partially burnt trunk, with green needles remain in the tree crown. The forest stands suffered fire and stolen felling disturbances are shown in Fig. 2.

We used a GPS receiver (Garmin eTrex 309x, Beijing, China) to record the coordinates of sample plots with an accuracy of $<3 \mathrm{~m}$. In each plot, the diameter at breast height (DBH), species name, and status (infected or uninfected) of each tree with a $\mathrm{DBH}>8 \mathrm{~cm}$ were recorded. As for the canopy density of the sample plots, we used the canopy projection method to calculate canopy closure (Bunnell and Vales, 2011). Soils of the 20-cm depth were collected at four corners and the central point of each plot and 
mixed well, and the Kjeldahl method was used to obtain soil total nitrogen content (Simard et al., 2012; Bao and Jiang, 2013). We recorded the topographic characteristics, including elevation, aspect, and slope for each sample plot. Aspect was converted into a south-west-ness index ranging between - 1 and 1 in the subsequent multivariate statistical analysis (Beers et al., 1966). In addition, we used a digital elevation model (DEM) (Aster GDEM 30 m resolution, 2021) to calculate the total radiation of each plot from April to August each year. RTB penetrates the base or shallow roots of pine trees and feeds on phloem tissue, forming funnel-shaped entrance holes in the trunk base (Fig. 2). Therefore, we recorded the number of RTB entrance holes in the sample plots to represent the damage degree, which was used as a response variable in model construction statistics.

\section{Forest Landscape Structure}

We acquired two remote sensing images of Gaofen-2 (China Center for Resources Satellite Data and Application, 2020) covering the whole study area in September 2017 to calculate the forest landscape structure of the buffering zone with a radius of $250 \mathrm{~m}$ around each sample plot. The buffering zone with a radius of $250 \mathrm{~m}$ is a suitable scale for the bark beetle's response to disturbances (Komonen and Kouki, 2008). We used the random forest algorithm (Breiman, 2001) to classify land cover types based on remote sensing images, and the classification accuracy was $81.54 \%$ at 1-m resolution (Table S1). Land cover types were classified into six categories: Chinese pines, larches, broad-leaved trees, grasslands, farmlands, and residence communities. The conifer and broad-leaved trees were assigned as forests and other categories as open habitats (non-forests). Finally, we measured the percentage of total forest coverage (forest isolation) in the buffering zone area with a radius of $250 \mathrm{~m}$ around the sample plot as a representative of forest structure at the landscape level (Castagneyrol et al., 2019; Wang et al., 2021). In addition, we also measured the $\mathrm{Al}$ index of forests and COHESION index of Chinese pine patches to indicate the degree of forest fragmentation and connectivity of host patches, respectively (Bone et al., 2013; Seidl et al., 2015; Wang et al., 2019). In order to avoid the influence of spatial overlap on the representativeness of these landscape variables, the sampling points were spaced at least $500 \mathrm{~m}$ apart.

Moreover, the forest coverage of the buffering zone was maintained between $13 \%$ and $98 \%$ to ensure the reasonable distribution of these forest landscape variables. All landscape- and stand-level variables used for data analysis are shown in Table 1. The detailed descriptions of remote sensing image preprocessing, classification, and landscape index calculation are available in Supplementary Materials.

\section{Statistical analysis}

To explore the effects of forest landscape structure and stand-level factors on RTB damage under different disturbance conditions, we analyzed the data in three ways. First, we used generalized linear mixed models (GLMMs) and the data obtained from 109 sample plots to explore the factors affecting RTB damage. The degree of fire and stolen felling were not quantified, instead, these two disturbances were considered as binary variables, that is, yes or no. Second, GLMMs and the data of 79 undisturbed sample plots were used to explore the factors influencing RTB damage under non-disturbance conditions. 
In the GLMM, time was set as a random effect, stand- and landscape-scale variables were set as fixed effects. Third, since most of the sample plots disturbed by fire and stolen felling were investigated in 2019 with no random effect, we used generalized linear models (GLMs) to explore the factors affecting RTB damage under disturbance conditions. The data were the sum of 15 plots disturbed by fire and 16 plots disturbed by stolen felling.

Before constructing the models, explanatory variables were log-transformed to enhance the model's convergence stability. A preliminary analysis showed that our data were over dispersed, so we employed the negative binomial error distribution and log link function, which would provide better parameter estimates than the Poisson distribution (Zuur et al., 2009). The information-theoretic approach based on the corrected Akaike's information criterion (AICC) was applied to remove non-significant terms (Grueber et al., 2011). We used the "dredge" and "get.models" functions in the R package MuMIn (Bartoń, 2019) to generate all possible models and selected the top ranked models with a $\triangle A I C c$ value (i.e., AICc - AlC $c_{\min }$ ) $<2$ (Bloom et al., 2021). The variance expansion factor (VIF) of models was calculated to evaluate the collinearity between explanatory variables. The result showed the VIF values were less than 2 , indicating that the collinearity between explanatory variables was low. Model averaging was performed to produce the Akaike weight and model-averaged partial regression coefficient for each variable. The relative importance value of each variable was quantified by the sum of the Akaike weights for each model in which the variable appeared. Finally, we calculated the $\mathrm{R}^{2}$ of the best model (with a minimum AICc value) to observe the goodness of fit.

Results from the above analyses indicated that disturbance and forest isolation significantly affected the occurrence of RTB in the Heilihe National Nature Reserve. In order to further explore whether there were significant differences between different disturbances in affecting RTB damage, a Kruskal-Wallis test and a subsequent pairwise comparison were conducted. In addition, by applying a similar method to Wang et al. (2021), we divided the forest stands into simple forest landscape structure (high forest isolation: $<40 \%$ ) and complex forest landscape structure (low forest isolation: > 40\%), and the KruskalWallis test was conducted under disturbance and non-disturbance conditions to compare differences between them. All statistical analyses were performed in the $\mathrm{R}$ statistical programming environment $(\mathrm{R}$ Core Team, 2020) including the packages arm (Gelman, 2008), Ime4 (Krasnov et al., 2019), MuMln (Bartoń, 2019; Lukacs et al., 2009), piecewiseSEM (Nakagawa et al., 2017), and glmmTMB (Brooks et al., 2017). 
Table 1

List of explanatory variables used in model analysis

\begin{tabular}{|llll|}
\hline Variable category & Variable & $\begin{array}{l}\text { Scale of } \\
\text { measurement }\end{array}$ & Variable description \\
\hline Stand-level factors & DBH $(\mathrm{cm})$ & Stand & Stand mean DBH \\
\cline { 2 - 4 } & Canopy density $(\%)$ & Stand & Degree of canopy closure \\
\cline { 2 - 4 } & Slope $\left(^{\circ}\right)$ & Stand & Stand slope \\
\hline Aspect $\left(^{\circ}\right)$ & Stand & Stand orientation \\
\hline Elevation $(\mathrm{m})$ & Stand & Stand elevation \\
\hline Forest structure factors & Total $\mathrm{N}(\mathrm{g} / \mathrm{kg})^{\text {Forest isolation }}$ & Stand & Total nitrogen of soil \\
\cline { 2 - 4 } & Landscape & The area proportion of forest \\
\cline { 2 - 4 } & COHESION & Landscape & The fragmentation degree of forest \\
\cline { 2 - 4 } & Landscape & The connectivity of host patches \\
\hline
\end{tabular}

\section{Results}

\section{Variables affecting RTB damage}

The average number of entrance holes in each plot was $51.6(S E=6.81)$. Fire (estimate $=5.40, P<0.001)$ and stolen felling (estimate $=6.53, \mathrm{P}<0.001$ ) were the most important factors among all analyzed variables, which had significant positive effects on the number of RTB entrance holes (Table 2). In addition, the south-west-ness index (aspect; estimate $=0.63, \mathrm{P}<0.001$ ) from northeast to southwest had a positive effect on RTB damage (Table 2 and Fig. 3a), while the forest landscape structure factors (Forest isolation and COHESION) did not play a role in predicting the occurrence of RTB (Table 2).

\section{Plots under non-disturbance conditions}

The average number of RTB entrance holes in each plot of this group was 20.8 (SE =3.82). Similar to the above analysis, aspect (estimate $=1.33, \mathrm{P}<0.001$ ) significantly affected RTB damage in forest stands free from natural and human disturbances (Table 2). Canopy density had a significant positive relationship with RTB damage (Table 2). The number of RTB entrance holes decreased with the increase of canopy density (Fig. 3b). Altitude and solar radiation were present in the optimal model, but these two factors did not significantly affect the occurrence of RTB. Similarly, in undisturbed forest stands, the forest structure factors were not able to predict the occurrence of RTB.

\section{Plots disturbed by fire and stolen felling}


The average number of RTB entrance holes in plots under disturbance conditions was 121.0 (SE = 14.88). Forest isolation significantly affected RTB damage among all variables (Table 2). The exponentially negative relationship between RTB damage and forest isolation indicated that with the increasing forest patches, stands disturbed by fire or stolen felling were less vulnerable to RTB outbreak (Fig. 3c).

\section{Nonparametric test for important variables}

Based on the nonparametric test, the degree of RTB damage in forest stands disturbed by fire and stolen felling was significantly higher than that in undisturbed forest stands (Fig. 4a). The frequency of RTB occurrence was higher in forest stands disturbed by fire than that in forest stands disturbed by stolen felling, but the difference was not significant. The comparison between the effects of forest isolation on RTB damage under disturbance and non-disturbance conditions showed that in disturbed stands, the frequency of RTB occurrence in forest stands with a high forest isolation value was significantly lower than that in forest stands with a low forest isolation value, but this difference was not observed between those in undisturbed stands (Fig. 4b). 
Table 2

Summary of the model averaging procedure assessing effects of stand- and landscape-level factors on RTB damage under different disturbance conditions.

\begin{tabular}{|c|c|c|c|c|c|c|}
\hline & Estimate & $\begin{array}{l}\text { Std. } \\
\text { error }\end{array}$ & $\begin{array}{l}\mathrm{z-} \\
\text { value }\end{array}$ & P-value & $\begin{array}{l}\text { Relative } \\
\text { importance }\end{array}$ & $\mathrm{R}^{2}$ \\
\hline Variables & & & & & & $\begin{array}{l}0.56 \\
(0.60)\end{array}$ \\
\hline Intercept & 6.04 & 4.68 & 1.28 & 0.200 & & \\
\hline Canopy density & -5.57 & 3.34 & 1.65 & 0.099 & 0.57 & \\
\hline Aspect & 0.63 & 0.23 & 2.73 & $0.006^{* *}$ & 0.85 & \\
\hline Fire & 5.40 & 0.92 & 5.80 & 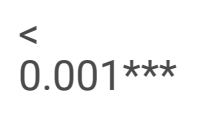 & 1.00 & \\
\hline Felling & 6.53 & 0.92 & 7.03 & $\begin{array}{l}<.001 * \star \star \\
0 .\end{array}$ & 1.00 & \\
\hline $\begin{array}{l}\text { Undisturbed } \\
\text { condition }\end{array}$ & & & & & & $\begin{array}{l}0.37 \\
(0.47)\end{array}$ \\
\hline Intercept & 19.03 & 12.79 & 1.48 & 0.140 & & \\
\hline Canopy density & -9.26 & 4.32 & 2.11 & $0.035^{\star}$ & 1 & \\
\hline Aspect & 1.33 & 0.38 & 3.34 & $\left\langle .001^{\star \star \star}\right.$ & 1 & \\
\hline Elevation & -5.07 & 2.95 & 1.69 & 0.091 & 0.56 & \\
\hline Solar radiation & 1.73 & 1.16 & 1.47 & 0.141 & 0.48 & \\
\hline \multicolumn{7}{|c|}{ Disturbed condition } \\
\hline Intercept & 5.64 & 3.66 & 1.53 & 0.127 & & 0.33 \\
\hline Forest isolation & -2.21 & 0.81 & 2.62 & $<0.009 * \star$ & 0.54 & \\
\hline Canopy density & 7.05 & 3.35 & 2.02 & $0.044^{\star}$ & 0.35 & \\
\hline
\end{tabular}

\section{Discussion}

\section{Effects of fire and stolen felling on RTB damage}

In line with many previous studies (Komonen and Kouki, 2008; Toivanen et al., 2009; Westlind and Kelsey, 2019), our results showed that fire and stolen felling can significantly promote RTB invasion. These two factors are the most important variables to predict RTB damage in our model (relative importance $=1$; 
Table 2). The aggressive behavior of RTB can be attributed largely to their sensitivity to ethanol and monoterpenes (such as 3-carene) produced in stressed woody phloem (Kelsey and Westlind, 2017, 2018).

Hekkala et al. (2020) has shown that the number of recently attacked spruce in gap-cut stands increased significantly compared with that of burnt stands. This finding contrasts with our study in which no significant difference was observed between felled and burnt stands. This phenomenon may be related to the sampling time after fire and fire intensity. In general, after three years of fire, the burnt forest stands are less attractive to bark beetles due to the decrease in the concentration of attractive volatiles (Westlind and Kelsey, 2019). Moreover, the stands burnt by high intensity fire are not favored by bark beetles due to the destruction of stem phloem (Kulakowski and Jarvis, 2013). The sample plots in our study were located at the edge of burnt stands within one to two years after fire, which were characterized as lowintensity fire. In addition, a small amount of fallen trees in plots disturbed by stolen felling could still attract a large number of RTBs to harm the fallen and surrounding healthy pine trees. It is worth noting that the current forest management strategies to deal with RTB damage mostly focus on hanging traps or clearing burnt woods in forests after fire, while ignoring the strong attraction of fallen woods after stolen felling to RTB. The new control strategy should simultaneously consider the attraction of woods in forests under natural (e.g., fire) and human disturbances (e.g., stolen felling) to RTB.

\section{Key factors affecting RTB damage in the absence of fire and human disturbances}

The factors affecting bark beetle damage are associated with the stage of outbreak (Simard et al., 2012). In the endemic population phase, stand-scale attributes, such as tree vigor, tree size, and canopy density, determine the outcome of bark beetle damage (Jakus et al., 2011; Lausch et al., 2011; Mezei et al., 2014). When bark beetle population increases, landscape-level factors, such as host connectivity and forest structure, outperform in predicting stand sensitivity (Simard et al., 2012; Seidl et al., 2015). The connectivity of host patches is the key for bark beetles to locate their hosts quickly in the outbreak period when the population density is high, while in the period when the population density is low, bark beetles prefer to damage stands at a small scale due to the widespread of hosts (Raffa et al., 2008; Seidl et al., 2015). Bone et al. (2013) found that forest structure (Al index) played different roles in different stages of the mountain pine beetle outbreak, and forests with low fragmentation were more seriously damaged in the late stage of outbreak. All the above results are consistent with our findings. In the early stage of RTB invasion, the factors affecting RTB damage were mainly small-scale stand factors, such as aspect and canopy density, while large-scale landscape factors did not play a role in the absence of natural and human disturbances (Table 2).

We found that aspect played an important role in both total variables and undisturbed condition analyses (Table 2). South-facing stands showed a higher degree of RTB damage compared to stands facing other directions. South-facing stands are more sensitive to bark beetles, because higher levels of solar radiation may reduce tree vitality and increase beetle survival (Coops et al., 2006; Lausch et al., 2011). Stands with lower canopy closure are more likely to be attacked by bark beetles, because relatively higher temperatures in such stands are more attractive to bark beetles (Netherer and Nopp-Mayr, 2005; Pasztor 
et al., 2014). Therefore, it is believed that aspect and canopy density are associated with solar radiation and stand temperature, respectively, and the significant role solar radiation plays during bark beetle invasion has also been revealed in many other studies (Kautz et al., 2013; Chen et al., 2014; Mezei et al., 2019). However, we did not observe a high relative importance in solar radiation in our study, which was present in the optimal model but was not significant. A possible explanation may be that the effect of extremely high radiation on RTB invasion is neutralized by the long-term cumulative radiation calculation (April to September).

\section{Effects of forest landscape structure on RTB damage in the presence of disturbance}

The Al index of forest structure was removed because of its strong association with forest isolation ( $R=$ 0.73; Fig. S2); thus, forest isolation was mainly used to represent different forest structures. Our results showed that forest structure played different roles under different disturbance conditions (presence or absence). Different from the non-disturbance condition, forest landscape structure could significantly affect RTB invasion in the presence of disturbance. The average distance of RTB dispersal flight in forests is beyond $500 \mathrm{~m}$ (Jones et al., 2019). Within a radius of $250 \mathrm{~m}$, the forest structure with a high proportion of open habitats (non-forest areas) was conducive to RTB dispersal from the surrounding areas to disturbed forests rich in ethanol and monoterpenoid volatiles. However, under non-disturbance condition, RTB prefers to randomly select weak host trees in situ for feeding and mating, which is also the reason why landscape indicators could not alter the preference of RTB in selecting the hosts in the early stage of outbreak (Raffa et al., 2008; Walter and Platt, 2013). Hekkala et al. (2020) explored the effects of the proportion of broad-leaved trees and spruce forests within a radius of $500 \mathrm{~m}$ around disturbed plots on the abundance of Ips typographus. Although the above landscape indicators did not perform well in regression models, they showed a trend (negative correlation) consistent with that observed in our study. Therefore, the present study, which emphasizes the potential importance of disturbance and forest landscape structure during RTB spread, not only contributes to expanding the understanding of the roles large-scale factors play under different disturbance conditions but also assists in the implementation of pest management programs.

Interestingly, we found that canopy density, instead of DBH (Kulakowski and Jarvis, 2013), significantly affected the occurrence of RTB in disturbed plots. Canopy density also exhibited a positive correlation with the number of RTB entrance holes in disturbed plots, which was not observed in undisturbed plots. During the field survey, we did not find the preference of RTB in tree size (DBH), and the high canopy density of the sample plots may lead to an increase in host tree abundance, thus promoting the attraction to RTB.

\section{Conclusion}

In this study, we explored the effects of disturbance and multi-scale factors on RTB damage in 109 forest stands in the Heilihe National Nature Reserve. We found that natural and human disturbances could significantly promote the occurrence of RTB. In the absence of disturbance, small-scale stand factors 
(aspect and canopy density) play an important role in the prediction of RTB damage. In the presence of fire and human disturbances, forest landscape structure (forest isolation) could significantly affect RTB damage. Our results expand the understanding of the influence of forest structure on RTB damage under different disturbance conditions and will help in more accurate predictions of future patterns of outbreaks, which take both natural and human disturbances into consideration. The impact of forest isolation on RTB invasion in the presence of disturbance should be considered in forest management. However, it is not clear whether the influence of forest structure on RTB dispersal will be weakened under disturbance conditions during RTB outbreak when the population density is high, which will be explored in our future study.

\section{Declarations}

\section{Acknowledgment}

We would like to thank the Heilihe National Nature Reserve Farm for supporting the field experiments and data collection. The authors would like to thank TopEdit institution for linguistic assistance during preparation of this manuscript.

\section{Authors' contributions}

Zhongyi Zhan conceived and designed research. Zhongyi Zhan conducted experiments. Zhongyi Zhan and Lixia Wang analyzed data and wrote the manuscript. All authors participated in review and revision of the manuscript.

\section{Funding}

This study was supported by The National Key Research \& Development Program of China "Research on key technologies for prevention and control of major disasters in plantation" (2018YFD0600200) and the Science and Technology Planning Project of Beijing "Key technologies for prevention and control of major pests in Beijing ecological public welfare forests" (Z191100008519004)

\section{Availability of data and materials}

The datasets analyzed in this study are available from the corresponding author on reasonable request.

\section{Ethics approval and consent to participate}

Not applicable.

\section{Consent for publication}

Not applicable.

\section{Competing interests}


The authors declare that they have no competing interests.

\section{References}

1. Abbott B, Stennes B, Cornelis van Kooten G (2009) Mountain pine beetle, global markets, and the British columbia forest economy. Can J Forest Res 39(7):1313-1321. https://doi.org/10.1139/X09049

2. Bao SD, Jiang RF (2013) Determination of soil organic matter and total nitrogen. In: Bao SD (ed) Soil agrochemical analysis. China Agricultural press, Beijing, pp 30-48

3. Barclay HJ, Li C, Benson L, Taylor S, Shore T (2005) Effects of fire return rates on traversability of lodgepole pine forests for mountain pine beetle (Coleoptera: Scolytidae) and the use of patch metrics to estimate traversability. Can Entomol 137(5):566-583

4. Bartoń K (2019) MuMIn: Multi-Model Inference. R package version 1.43.6. http://CRAN.Rproject.org/package=MuMIn

5. Bloom EH, Wood TJ, Hung K-LJ, Ternest JJ, Ingwell LL, Goodell K, Kaplan I, Szendrei Z (2021) Synergism between local- and landscape-level pesticides reduces wild bee floral visitation in pollinator-dependent crops. J Appl Ecol 58(6):1187-1198. https://doi.org/10.1111/1365-2664.13871

6. Bone C, White JC, Wulder MA, Robertson C, Nelson TA (2013) Impact of Forest Fragmentation on Patterns of Mountain Pine Beetle-Caused Tree Mortality. Forests 4(2):279-295. https://doi.org/10.3390/f4020279

7. Breiman L (2001) Random Forests. Mach Learn 45(1):5-32. https://doi.org/10.1023/A:1010933404324

8. Bunnell F, Vales D (2011) Comparison of methods for estimating forest overstory cover: differences among techniques. Can J For Res 20(1):101-107. https://doi.org/10.1139/x90-014

9. Campbell EM, MacLean DA, Bergeron Y (2008) The severity of budworm-caused growth reductions in balsam fir/spruce stands varies with hardwood content of surrounding forest landscapes. For Sci 54(2):195-205

10. Castagneyrol B, Giffard B, Valdés-Correcher E, Hampe A (2019) Tree diversity effects on leaf insect damage on pedunculate oak: The role of landscape context and forest stratum. For Ecol Manag 433:287-294. https://doi.org/10.1016/j.foreco.2018.11.014

11. Chen H, Ott P, Wang J, Ebata $T$ (2014) A positive response of mountain pine beetle to pine forestclearcut edges at the landscape scale in British Columbia, Canada. Landscape Ecol 29(9):16251639. https://doi.org/10.1007/s10980-014-0090-3

12. Cheng C, Zhou F, Lu M, Sun J (2015) Inducible pine rosin defense mediates interactions between an invasive insect-fungal complex and newly acquired sympatric fungal associates. Integr Zool 10(5):453-464. https://doi.org/10.1111/1749-4877.12138

13. China Meteorological Data Service Center (2021) National Climatic Data Center 1981-2010 annual normals, Lingyuan, Liaoning. http://data.cma.cn/. Accessed 9 Jan 2021 
14. Coops NC, Johnson M, Wulder MA, White JC (2006) Assessment of QuickBird high spatial resolution imagery to detect red attack damage due to mountain pine beetle infestation. Remote Sens Environ 103(1):67-80. https://doi.org/10.1016/j.rse.2006.03.012

15. David JG, David FG, Timothy TW (2012) Causes of Variation in Wood-Boring Beetle Damage in FireKilled Black Spruce Forests in the Central Boreal Forest of Quebec. Ecoscience 19(4):398-403. https://doi.org/10.2980/19-4-3568

16. Grueber CE, Nakagawa S, Laws RJ, Jamieson IG (2011) Multimodel inference in ecology and evolution: challenges and solutions. J Evolution Biol 24(4):699-711. https://doi.org/10.1111/j.14209101.2010.02210.x

17. Hansen WD, Chapin FS, Naughton HT, Rupp TS, Verbyla D (2016) Forest-landscape structure mediates effects of a spruce bark beetle (Dendroctonus rufipennis) outbreak on subsequent likelihood of burning in Alaskan boreal forest. For Ecol Manag 369:38-46. https://doi.org/10.1016/j.foreco.2016.03.036

18. Hart SJ, Veblen TT, Mietkiewicz N, Kulakowski D (2015) Negative feedbacks on bark beetle outbreaks: widespread and severe spruce beetle infestation restricts subsequent infestation. PloS one 10(5):e0127975. https://doi.org/10.1371/journal.pone.0127975

19. Havašová $M$, Ferenčík J, Jakuš R (2017) Interactions between windthrow, bark beetles and forest management in the Tatra national parks. For Ecol Manag 391:349-361.

https://doi.org/10.1016/j.foreco.2017.01.009

20. Hekkala A-M, Kärvemo S, Versluijs M, Weslien J, Björkman C, Löfroth T, Hjältén J (2020) Ecological restoration for biodiversity conservation triggers response of bark beetle pests and their natural predators. Forestry 94. https://doi.org/10.1093/forestry/cpaa016

21. Jakus R, Zají, kova L, Cudlín P, Bla, enec M, Tur, ani M, Je, ík M, Lieutier F, Schlyter F (2011) Landscape-scale Ips typographus attack dynamics: from monitoring plots to GIS-based disturbance models. iForest 4(6):256-261. https://doi.org/10.3832/ifor0589-004

22. Jones KL, Shegelski VA, Marculis NG, Wijerathna AN, Evenden ML (2019) Factors influencing dispersal by flight in bark beetles (Coleoptera: Curculionidae: Scolytinae): from genes to landscapes. Can J Forest Res 49(2):1024-1041. https://doi.org/10.1139/cjfr-2018-0304

23. Kautz M, Schopf R, Ohser J (2013) The "sun-effect": microclimatic alterations predispose forest edges to bark beetle infestations. Eur J Forest Res 132(3):453-465. https://doi.org/10.1007/s10342013-0685-2

24. Kelsey RG, Westlind DJ (2018) Attraction of red turpentine beetle and other Scolytinae to ethanol, 3carene or ethanol + 3-carene in an Oregon pine forest. Agr For Entmol 20(2):272-278. https://doi.org/10.1111/afe.12257

25. Kelsey RG, Westlind DJ (2017) Ethanol and primary attraction of red turpentine beetle in fire stressed ponderosa pine. For Ecol Manag 396:44-54. https://doi.org/10.1016/j.foreco.2017.04.009

26. Klutsch JG, Negrón JF, Costello SL, Rhoades CC, West DR, Popp J, Caissie R (2009) Stand characteristics and downed woody debris accumulations associated with a mountain pine beetle 
(Dendroctonus ponderosae Hopkins) outbreak in Colorado. For Ecol Manag 258(5):641-649. https://doi.org/10.1016/j.foreco.2009.04.034

27. Komonen A, Kouki J (2008) Do restoration fellings in protected forests increase the risk of bark beetle damages in adjacent forests? A case study from Fennoscandian boreal forest. For Ecol Manag 255(11):3736-3743. https://doi.org/10.1016/j.foreco.2008.03.029

28. Kulakowski D, Jarvis D (2013) Low-severity fires increase susceptibility of lodgepole pine to mountain pine beetle outbreaks in Colorado. For Ecol Manag 289:544-550. https://doi.org/10.1016/j.foreco.2012.10.020

29. Lausch A, Fahse L, Heurich M (2011) Factors affecting the spatio-temporal dispersion of Ips typographus (L.) in Bavarian Forest National Park: A long-term quantitative landscape-level analysis. For Ecol Manag 261(2):233-245. https://doi.org/10.1016/j.foreco.2010.10.012

30. Mezei P, Grodzki W, Blaženec M, Škvarenina J, Brandýsová V, Jakuš R (2014) Host and site factors affecting tree mortality caused by the spruce bark beetle (Ips typographus) in mountainous conditions. For Ecol Manag 331:196-207. https://doi.org/10.1016/j.foreco.2014.07.031

31. Mezei P, Potterf M, Škvarenina J, Rasmussen JG, Jakuš R (2019) Potential Solar Radiation as a Driver for Bark Beetle Infestation on a Landscape Scale. Forests 10(7):604. https://doi.org 10.3390/f10070604

32. Negrón JF, McMillin JD, Anhold JA, Coulson D (2009) Bark beetle-caused mortality in a droughtaffected ponderosa pine landscape in Arizona, USA. For Ecol Manag 257(4):1353-1362. https://doi.org/10.1016/j.foreco.2008.12.002

33. Nelson T, Boots B, Wulder MA, Shore T, Safranyik L, Ebata T (2006) Rating the susceptibility of forests to mountain pine beetle infestations: the impact of data. Can J Forest Res 36(11):28152825. https://doi.org/10.1139/x06-163

34. Netherer S, Nopp-Mayr U (2005) Predisposition assessment systems (PAS) as supportive tools in forest management-rating of site and stand-related hazards of bark beetle infestation in the High Tatra Mountains as an example for system application and verification. For Ecol Manag 207(12):99-107. https://doi.org/10.1016/j.foreco.2004.10.020

35. Pasztor F, Matulla C, Rammer W, Lexer MJ (2014) Drivers of the bark beetle disturbance regime in Alpine forests in Austria. For Ecol Manag 318:349-358. https://doi.org/10.1016/j.foreco.2014.01.044

36. Raffa KF, Aukema BH, Bentz BJ, Carroll AL, Hicke JA, Turner MG, Romme WH (2008) Cross-scale Drivers of Natural Disturbances Prone to Anthropogenic Amplification: The Dynamics of Bark Beetle Eruptions. Bioscience 58(6):501-517. https://doi.org/10.1641/B580607

37. Schroeder M (2009) Colonization of storm gaps by the spruce bark beetle: Influence of gap and landscape characteristics. Agr For Entmol 12:29-39. https://doi.org/10.1111/j.14619563.2009.00447.x

38. Seidl R, Donato DC, Raffa KF, Turner MG (2016) Spatial variability in tree regeneration after wildfire delays and dampens future bark beetle outbreaks. P Natl Acad Sci USA 113(46):13075-13080. 
https://doi.org/10.1073/pnas.1615263113

39. Seidl R, Müller J, Hothorn T, Bässler C, Heurich M, Kautz M (2015) Small beetle, large-scale drivers: how regional and landscape factors affect outbreaks of the European spruce bark beetle. J Appl Ecol 53(2):530-540. https://doi.org/10.1111/1365-2664.12540

40. Simard M, Powell EN, Raffa KF, Turner MG (2012) What explains landscape patterns of tree mortality caused by bark beetle outbreaks in Greater Yellowstone? Global Ecol Biogeoge 21(5):556-567. https://doi.org/10.1111/j.1466-8238.2011.00710.x

41. Tang G, Cong X, Liu S, Zhao X, Wang Y, Sun B, Zhang J (2019) Pre-endanger management and control mechanism and technology scheme for Dendroctonus valens. J Hebei For Sci Technol 220(1):72-74

42. Toivanen T, Liikanen V, Kotiaho JS (2009) Effects of forest restoration treatments on the abundance of bark beetles in Norway spruce forests of southern Finland. For Ecol Manage 257(1):117-125. https://doi.org/10.1016/j.foreco.2008.08.025

43. Walter JA, Platt RV (2013) Multi-temporal analysis reveals that predictor of mountain pine beetle infestation change during outbreak cycles. For Ecol Manag 302:308-318. https://doi.org/10.1016/j.foreco.2013.03.038

44. Wang B, Tian C, Sun J (2019) Effects of landscape complexity and stand factors on arthropod communities in poplar forests 9(12):7143-7156. https://doi.org/10.1002/ece3.5285

45. Wang B, Tian C, Liang Y (2021) Mixed effects of landscape structure, tree diversity and stand's relative position on insect and pathogen damage in riparian poplar forests. For Ecol Manag 479:118555. https://doi.org/10.1016/j.foreco.2020.118555

46. Westlind DJ, Kelsey RG (2019) Predicting post-fire attack of red turpentine or western pine beetle on ponderosa pine and its impact on mortality probability in Pacific Northwest forests. For Ecol Manag 434:181-192. https://doi.org/10.1016/j.foreco.2018.12.021

47. White JC, Wulder MA, Brooks D, Reich R, Wheate RD (2005) Detection of red attack stage mountain pine beetle infestation with high spatial resolution satellite imagery. Remote Sens Environ 96(3):340-351. https://doi.org/10.1016/j.rse.2005.03.007

48. Xu H, Li N, Li Z (2006) The analysis of outbreak reason and spread directions of Dendroctonus valens. Plant Quar 20(5):278-280. https://doi.org/10.3969/j.issn.1005-2755.2006.05.005

49. Yan Z, Sun J, Don O, Zhang Z (2005) The red turpentine beetle, Dendroctonus valens LeConte (Scolytidae): an exotic invasive pest of pine in China. Biodiversity Conserv 14(7):1735-1760. https://doi.org/10.1007/s10531-004-0697-9

50. Zhan Z, Yu L, Li Z, Ren L, Gao B, Wang L, Luo Y (2020) Combining GF-2 and Sentinel-2 Images to Detect Tree Mortality Caused by Red Turpentine Beetle during the Early Outbreak Stage in North China. Forests 11(2):172. https://doi.org/10.3390/f11020172

51. Zhao Z, Shen F, Liu J (2002) Red turpentine beetle are threatening China's forestry production. Plant Quar 16(2):86-88. https://doi.org/10.3969/j.issn.1005-2755.2002.02.009 
Figures

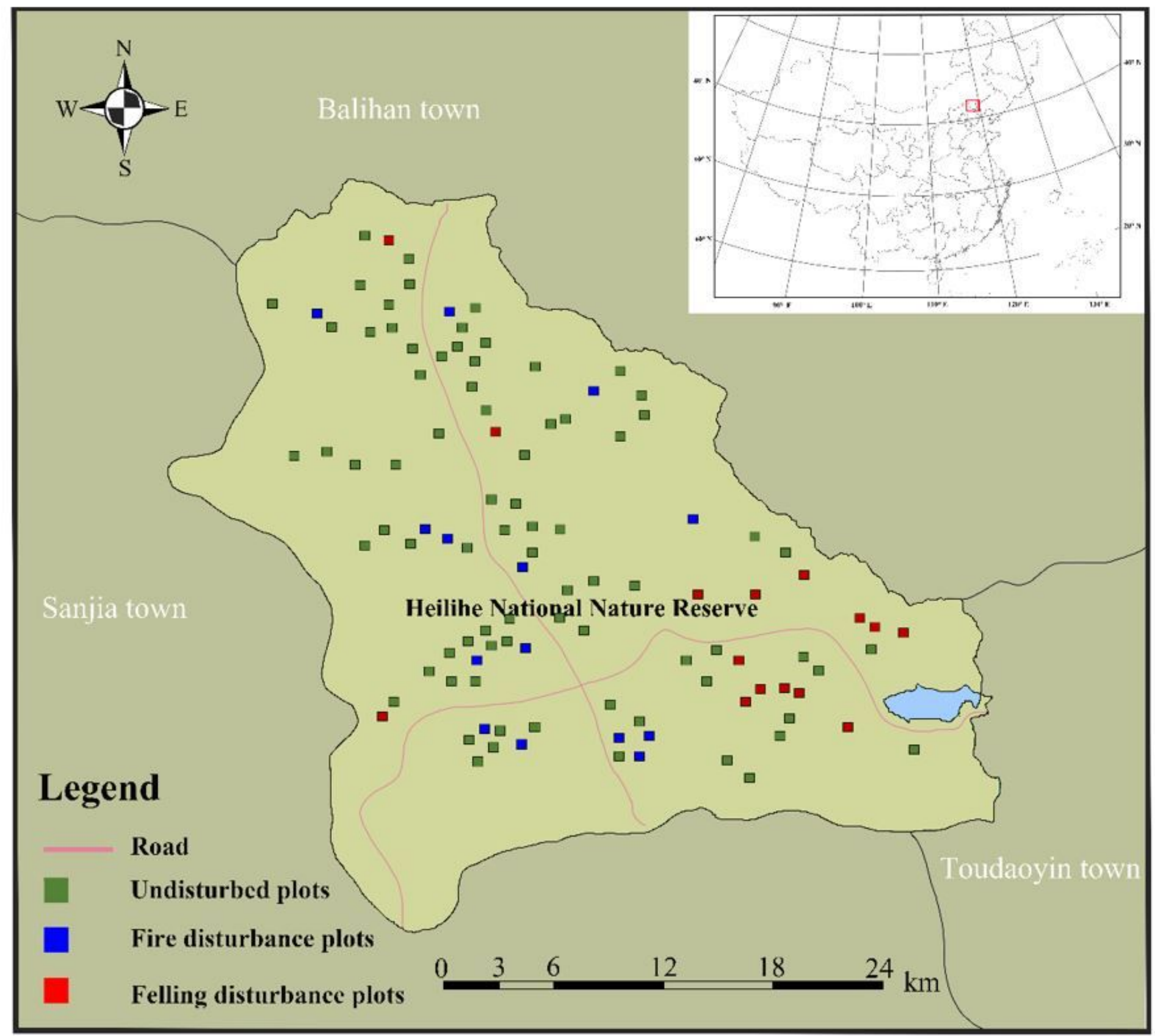

Figure 1

Distribution of sample plots in the study area. 
(a)

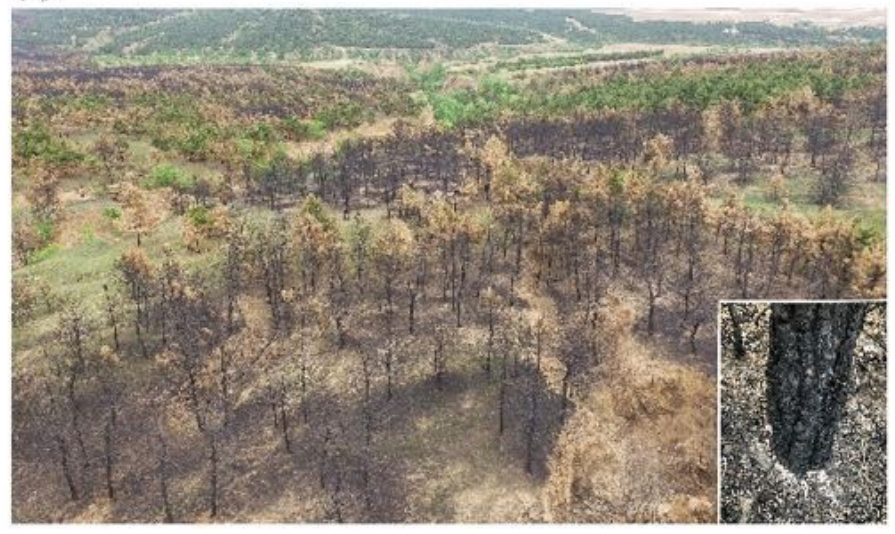

(b)

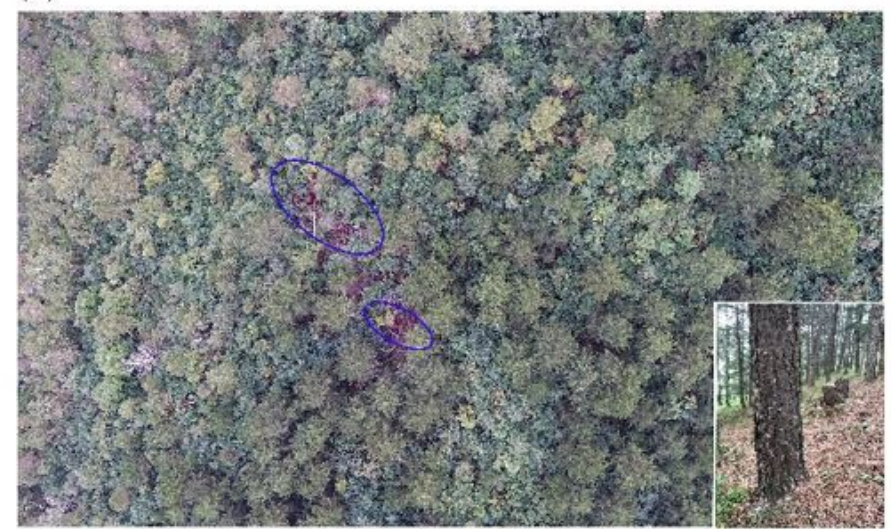

Figure 2

Sites under natural and human disturbances in the study area. (a) Forests after fire; (b) felled woods left after stolen felling.
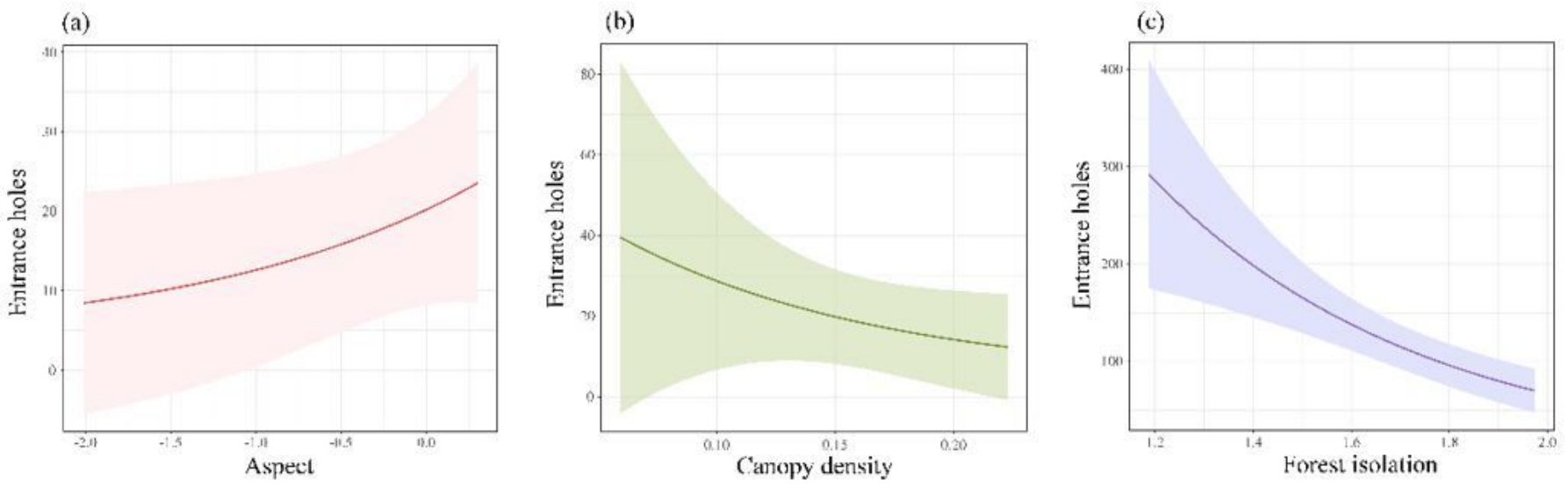

\section{Figure 3}

Model-averaged predictions and standard errors showing the response of RTB damage to (a) aspect ( $\mathrm{x}$ axis represents a change from northeast to southwest), (b) canopy density, and (c) forest isolation. 
(a)

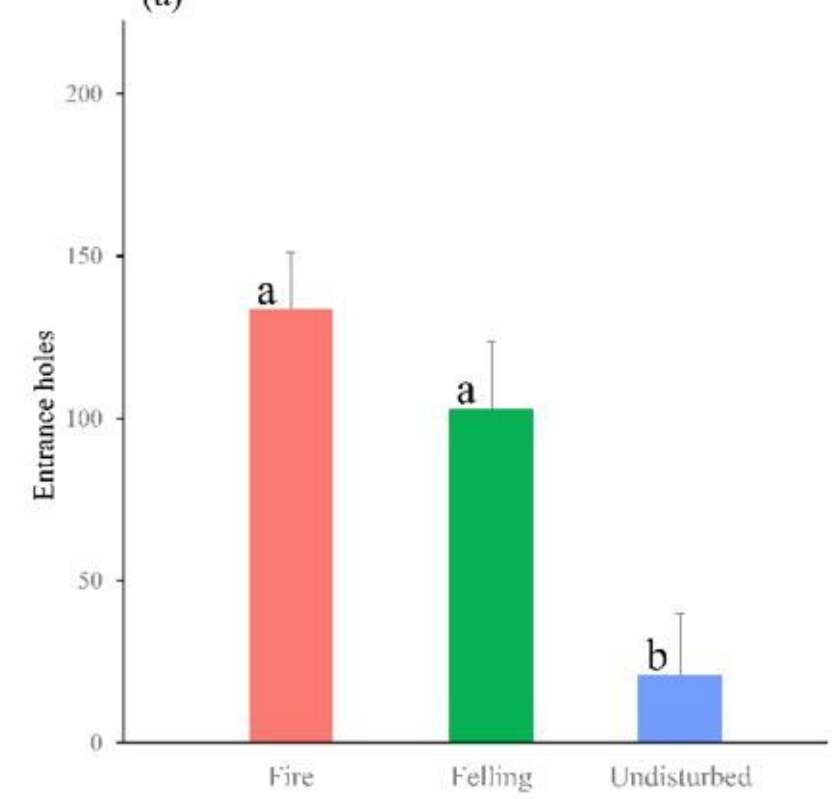

(b)

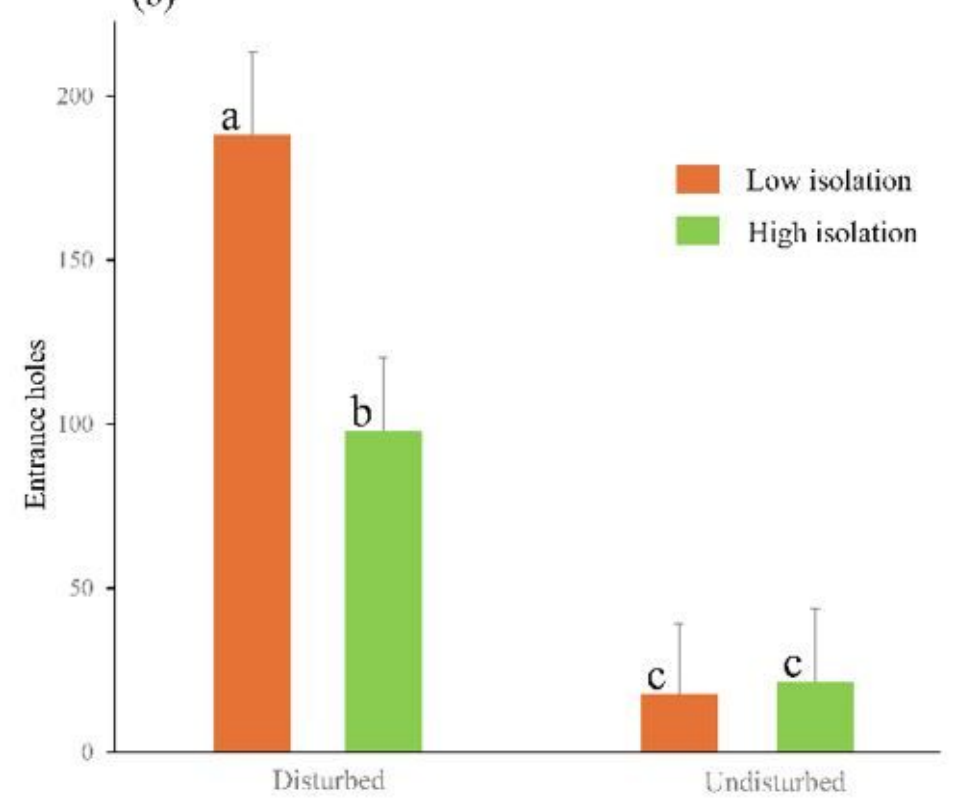

\section{Figure 4}

Effects of (a) disturbance (fire and stolen felling) and (b) forest isolation on RTB damage. High forest isolation refers to higher isolated landscapes, with $<40 \%$ forest; low forest isolation represents the opposite situation. Based on Kruskal-Wallis's post hoc tests, statistical significance was observed at the $\mathrm{P}<0.05$ level.

\section{Supplementary Files}

This is a list of supplementary files associated with this preprint. Click to download.

- AdditionalFile.docx 